\title{
Colonoscopy with Marking of Cancerous Polyp
}

National Cancer Institute

\section{Source}

National Cancer Institute. Colonoscopy with Marking of Cancerous Polyp. NCI

Thesaurus. Code C136342.

A procedure in which the location of a cancerous polyp is marked with a dye during colonoscopy, for the purpose of identifying the site for later, possible resection. 